\title{
Medulloblastoma cancer stem cells: molecular signatures and therapeutic targets
}

\author{
Hisham F Bahmad (1) , ${ }^{1,2}$ Robert J Poppiti ${ }^{1,3}$
}

- Additional material is published online only. To view please visit the journal online (http://dx.doi.org/10.1136/ jclinpath-2019-206246)

'Arkadi M Rywlin MD Department of Pathology and Laboratory Medicine, Mount Sinai Medical Center, Miami Beach, Florida, USA

${ }^{2}$ Department of Anatomy, Cell Biology and Physiological Sciences, Faculty of Medicine, American University of Beirut, Beirut, Lebanon

${ }^{3}$ Herbert Wertheim College of Medicine, Florida International University, Miami, Florida, USA

\section{Correspondence to}

Professor Robert J Poppiti, Arkadi M. Rywlin M.D.

Department of Pathology and Laboratory Medicine, Mount Sinai Medical Center, Miami Beach FL 33140, USA; Robert. Poppiti@msmc.com

Received 2 October 2019 Revised 12 December 2019 Accepted 16 December 2019 Published Online First 7 February 2020
Check for updates

(C) Author(s) (or their employer(s)) 2020. No commercial re-use. See rights and permissions. Published by BMJ.

To cite: Bahmad HF Poppiti RJ. J Clin Pathol 2020:73:243-249.

\section{ABSTRACT}

Medulloblastoma (MB) is the most common malignant primary intracranial neoplasm diagnosed in childhood. Although numerous efforts have been made during the past few years to exploit novel targeted therapies for this aggressive neoplasm, there still exist substantial hitches hindering successful management of MB. Lately, progress in cancer biology has shown evidence that a subpopulation of cells within the tumour, namely cancer stem cells (CSCs), are thought to be responsible for the resistance to most chemotherapeutic agents and radiation therapy, accounting for cancer recurrence. Hence, it is crucial to identify the molecular signatures and genetic aberrations that characterise those CSCS and develop therapies that specifically target them. In this review, we aim to give an overview of the main genetic and molecular cues that depict MB-CSCs and provide a synopsis of the novel therapeutic approaches that specifically target this population of cells to attain enhanced antitumorous effects and therefore overcome resistance to therapy.

\section{INTRODUCTION}

Medulloblastoma (MB) is the most common malignant primary intracranial neoplasm in children, accounting for around $20 \%$ of all paediatric brain tumours. ${ }^{1}$ It is a primitive neuroectodermal malignancy of the central nervous system that is believed to arise from neural stem cell precursors in the granular cell layer of the cerebellum. ${ }^{2}$ Specifically, many studies demonstrate that it originates from the remnants of the primitive neuroectoderm in the germinal matrix of the fourth ventricle roof, ${ }^{34}$ while other studies have reported a different origin for this invasive neoplasm: the external granular layer precursor cells. ${ }^{56} \mathrm{MB}$ is subdivided into four major entities at the molecular level ${ }^{7}: \mathrm{MB}^{\text {WNT }}$ activated $, \mathrm{MB}^{\text {SHH-activated,TP53-mutant }}, \mathrm{MB}^{\text {SHH-activated,TP53- }}$ wildype and $\mathrm{MB}^{\text {non-WNT/non-SHH }}$ (includes $\mathrm{MB}^{\text {non-WNT }}$ non-SHH, Group 3 and $\left.\mathrm{MB}^{\text {non-WNT/non-SHH, Group } 4}\right)$.

The incidence of $\mathrm{MB}$ ranges from 0.53 (children aged 0-4 years) to 0.16 (adolescents aged 15-19 years) per 100000 population in patients up to 19 years old, and affects males more than females (1.7 times more frequently in the age group $0-14$ years $)^{8}$ and white people more than black (1.7 times). ${ }^{9}$ The incidence continues to decline with age, reaching 0.06 per 100000 person-years by 55-64 years of age. ${ }^{9}$ The peak age at diagnosis of $\mathrm{MB}$ is 7 years, with more than $70 \%$ of all cases observed among children younger than 16 years of age, ${ }^{1011}$ and $10 \%-15 \%$ of patients diagnosed in infancy. ${ }^{9}$ Although aggressive, the 10 -year survival for patients with MB in the USA was found to be $64.9 \% .{ }^{8}$ This could be attributable to the multimodality treatment approach including surgical intervention, radiation therapy (RT) and chemotherapy. ${ }^{3}$

During the past decade, increased interest in understanding the molecular basis of $\mathrm{MB}$ has revealed new insights into the different molecular and signalling pathways that might contribute to the tumour's formation, progression and recurrence. In this regard, many articles have been published in the last few years tackling the role of cancer stem cells (CSCs) as principal drivers in $\mathrm{MB}$ initiation and relapse, and subsequently as potential therapeutic targets for this malignant neoplasm. ${ }^{12}$ Indeed, the CSC concept has become increasingly prominent ever since it was first proposed four decades ago, based on their self-renewal ability, potential to differentiate into the different types of cells and uninhibited growth pattern contributing to resistance to conventional therapies. ${ }^{13} 14$

CSCs were first identified in leukaemias in 1973 as a distinguished population of cells, embracing specific pro-oncogenic genetic signatures, that are capable of generating malignant haematopoietic colonies. ${ }^{15}$ With time, CSCs have been gradually identified in dedicated niches of many other tumours ${ }^{14}$ including MB in 2003. ${ }^{16}$ Indeed, CSCs had been isolated from human and mouse $\mathrm{MBs}^{17}$ and were shown to reside in a perivascular niche (PVN). ${ }^{18}$ The stem cell niche is referred to the microenvironment surrounding cancer cells, and is composed of supportive cells, extracellular matrix and factors needed to maintain cancer stemness. ${ }^{19}$ Although the niche in $\mathrm{MB}$ tumours is still largely undefined, ${ }^{20}$ a recent report by Calabrese et al ${ }^{18}$ revealed that CD133-positive MB-CSCs reside near endothelial cells and small vessels, and might function as a niche.

Highly tumourigenic MB cells have been shown to display features imitating those of neural stem and progenitor cells, such as upregulation of CD133, Nestin and Musashi (MSI1) ${ }^{21}$ (MSI1 $^{22}$ and Nestin are evolutionally conserved markers for central nervous system (CNS) progenitor cells and neuronal stem cells), as well as developmentally related genes, such as Ebfs. ${ }^{23}$ Here, we discuss the latest discoveries related to MB-CSC genetic signatures and the novel therapies that specifically target those cells based on the molecular cues they harbour.

\section{METHODOLOGY}

This review was conducted using the 'Preferred Reporting Items for Systematic Reviews and MetaAnalyses' (PRISMA) 2009 guidelines. We performed 
a comprehensive search using two databases, namely OVID/ Medline and PubMed, for mesh terms, keywords and combinations related to 'cancer stem cells' and 'medulloblastoma'. Complete search strategy is provided in online supplementary appendix S1. In total, 248 articles were retrieved through database search from inception to 15 September 2019. We inserted all articles into EndNote V.X8 referencing program, and excluded duplicates, abstracts, case reports, non-English articles, reviews, commentaries and editorials. As a result, a total of 105 articles were considered for full-text qualitative analysis and inclusion in the final review. Online supplementary appendix S2 illustrates the study flow chart of the review process according to PRISMA 2009 flow diagram guidelines.

\section{MB CLASSIFICATIONS AND CSCS}

Histologically, MB is classified into four main WHO-defined subsets $^{24}$ : classic MB, large-cell anaplastic, desmoplastic MB and $\mathrm{MB}$ with extensive nodularity (other variants such as medullomyoblastoma and melanotic do exist but are extremely rare). ${ }^{2}$ At a molecular level, and according to the latest consensus nomenclature, $M B$ is subdivided into four major entities ${ }^{7}$ : (1) $\mathrm{MB}^{\text {WNT }}$ activated (thought to originate from the lower rhombic lip), ${ }^{25} 26$ (2) $\mathrm{MB}^{\text {SHH-activated,TPS3-mutant }}$ and (3) $\mathrm{MB}^{\text {SHH-activated,TPS3-wildype }}$ (sonic hedgehog ( $\mathrm{SHH}$ ); arises from granular neuron progenitors in the external germinal layer), ${ }^{27} 28$ and (4) $\mathrm{MB}^{\text {non-WNT/non-SHH }}$ which comprises $\mathrm{MB}^{\text {non-WNT/non-SHH, Group } 3}$ (develops from cerebellar stem cells with high levels of MYC amplification and is considered the most aggressive among all subgroups ${ }^{29} 30$ and $\mathrm{MB}^{\text {non-WNT/non- }}$ SHH, Group 4 (the most prevalent yet still of unknown origin). ${ }^{31}{ }^{32}$ Noteworthy, genes that are mainly deregulated in MB, such as WNT, SHH and Notch, as well as the proto-oncogenes RTK (receptor tyrosine kinase) and MYC, are central to molecular pathways controlling cell cycle and growth of CSCs. ${ }^{33-35}$ Moreover, reports from retrospective studies reveal that several molecular and genetic aberrations that correlate with $\mathrm{MB}$ prognosis and outcome $e^{36-41}$ are also involved in the control of CSC stemness ${ }^{42-47}$ including neurotrophin-3 receptor, ${ }^{48}$ CD $15,{ }^{49-51}$ PTEN $,{ }^{52}{ }^{\text {MYC }},{ }^{53-55}$ ErbB2, ${ }^{56} \beta$-catenin, ${ }^{57}{ }^{58}$ survivin $^{59} 60$ and p55. ${ }^{61}$

Further exploration showed that other markers linked to CSCs might have a pivotal role in MB tumour formation and progression. ${ }^{62}$ For instance, Singh $e t a l^{17}$ were the first to reveal a role of CSC markers in $\mathrm{MB}$, where they found that injecting a small number as low as $100 C D 133+$ cells into immunodeficient mice could yield $\mathrm{MB}$ tumour formation in vivo, whereas tumour failed to develop with CD133 - cells even on increasing the number of injected cells to 100000 cells. In this regard, high mRNA levels of CD133 had been correlated with poor prognosis and increased likelihood of metastases in paediatric $\mathrm{MBS}^{63}$ This demonstrates the importance of identifying novel CSC biomarkers and genetic signals and incorporating them altogether with the currently available parameters to create new stratification schemes for MB. ${ }^{64}$ Such schemes may help to refine the management approaches for the different histological and molecular entities of this tumour. ${ }^{65-68}$ We will elaborate more on the various studied molecular signatures and therapeutic targets pertaining to MB-CSCs.

\section{MB-CSCS: FROM GENES TO THERAPIES}

Ever since the first MB-CSCs were isolated from human tissues in $2003(C D 133+\vee N e s t i n+)$ showing improved proliferation, self-renewal and differentiation in vitro, ${ }^{16}$ subsequent research has elucidated the genetic aberrations and molecular signatures pertaining to those CSCs, paving the way for novel therapeutic targets in this aggressive intracranial tumour.

\section{CD133 and its relation to other molecular signatures}

CD133 (prominin-1) is the most common cell surface antigen used to detect and isolate CSCs from various solid tumours. ${ }^{69}$ Physiologically, it induces WNT/ $\beta$-catenin signalling ${ }^{70-73}$ and has also been described as an important regulator of PI3K/Akt signalling in CSCs. ${ }^{7475}$ The use of this marker to identify MB-CSCs in paediatric tissue samples was first described by Singh et al, ${ }^{16} 17$ and the isolated CD133 + cells were termed brain tumour stem cells. These cells had the ability to grow into neurosphere-like clusters in vitro and to produce massive tumours on intracranial transplantation into NOD-SCID mice forebrains in vivo, expressing neural stem cell markers such as nestin. ${ }^{16}$ An alternative method for culturing MB-CSCs, other than the threedimensional (3D) neurospheres technique, has been proposed by de la Rosa $e t \mathrm{al}^{76}$ using laminin-precoated flasks that enable dedifferentiation of cells and enrich the stem-like cell population. Based on their high expression of CD133, CSCs possess the ability to resist apoptosis as well as $\mathrm{RT}^{77}$ and chemotherapeutic drugs. ${ }^{78}$

A study by Annabi et $a l^{79}$ demonstrated that members of the low-density lipoprotein receptor-related protein (LRP) family, including LRP-1, LRP-1b, LRP-5 and LRP-8, regulate the adaptive phenotype associated with CD133+ MB-CSCs. Another study by the same research group revealed that matrix metallopeptidase 9 and membrane type I-matrix metalloproteinase, which are major players in cancer cell invasion, metastasis and resistance to therapy, have crucial roles in maintaining the invasive phenotype of $C D 133+$ neurosphere-derived MB cells, while targeting those two molecules may reduce the formation of brain tumour stem cells. ${ }^{80}$

Inflammatory mediators such as cyclooxygenase-2 (COX2 ), an enzyme that converts arachidonic acid to prostaglandins, have been shown to be overexpressed in a variety of tumours, ${ }^{81}{ }^{82}$ including $\mathrm{MB} .{ }^{83}$ COX-2-derived prostaglandins have also been implicated in tumour growth and angiogenesis. ${ }^{84}$ Henceforth, the role of anti-inflammatory drugs in targeting MB-CSCs has recently been assessed, whereby a study was conducted by Chen $e t a l^{85}$ and Yang $e a^{8 l^{86}}$ to assess the enhancing effects of celecoxib on ionising radiotherapy (IR) of CD133 + MB cells. Results demonstrated that celecoxib significantly enhanced radiosensitivity of those $\mathrm{MB}$ cells in vitro and in vivo. ${ }^{85}{ }^{86}$ In the same milieu, resveratrol, a natural polyphenol derived from red wine, has been shown to inhibit proliferation and tumourigenicity of MB-CSCs and enhance radiosensitivity in treated MB-CSCs. ${ }^{87}$

One of the mechanisms contributing to chemotherapeutic resistance in many tumours is upregulation of X linked inhibitor of apoptosis protein and cellular inhibitor of apoptosis $1 / 2 .^{88}$ This applies to CD133+ MBCSCs, which displayed higher levels of both proteins and demonstrated hypersensitivity to treatment with small-molecule inhibitors of apoptosis proteins (IAP) inhibitors LCL161 and LBW242. ${ }^{88}$ Another pathway that plays a role in the maintenance of CD133+ MBCSCs was described by Chang et al, ${ }^{89}$ who treated those cells with a potent STAT3 inhibitor, cucurbitacin I. Results revealed that the latter treatment suppressed the CSC-like properties and stemness of MB-derived CD133+ cells and increased the apoptotic sensitivity of those cells to RT and chemotherapeutic drugs. ${ }^{89}$ Similarly, Garg et al and others showed that signal transducers and activators of the STAT3 
pathway are activated in CD133+ MB-CSCs through regulation of $c-M Y C$, a key genetic driver of $\mathrm{MB}^{\text {non-WNT/non-SHH, }}$ Group3 9091

An orthotopic xenograft model, named MB3W1, was established using cells derived from the malignant pleural effusions from a child with $\mathrm{MB}^{\text {non-WNT/non-SHH, Group } 3} .^{92}$ This model displayed CSC characteristics such as the ability to form neurospheres, high aldehyde dehydrogenase (ALDH) activity, expression of CD133/CD15 stem cell markers and high tumourigenicity in NOD-SCID mice. ${ }^{92}$ In a similar study by Friedman et $a l,{ }^{93}$ four human paediatric $\mathrm{MB}$ xenografts, mainly representing group 3 tumours, were used to prove that hypoxia increases CD133 as well as primary HSV-1 (herpes simplex virus) entry molecule nectin-1 (CD111) expression. Interestingly, MB cells expressing CD111 were also found to be highly sensitive to killing by clinically relevant oncolytic HSVs (G207 and M002) in vitro and in vivo. ${ }^{93}$

In a study by Lim et al, ${ }^{94}$ polymeric nanoparticle formulation of curcumin was used to assess its effect as a potential therapy for MB-CSCs. This compound is derived from the Indian spice turmeric and has been proven to harbour diverse effects on human diseases: proapoptotic, antiangiogenic, anti-inflammatory, immunomodulatory and antimitogenic effects. ${ }^{95} 96$ Treating MB cells with curcumin decreased anchorage-independent clonogenic growth, reduced the $\mathrm{CD} 133+$ stem-like population, attenuated insulin-like growth factor and STAT3 pathways, and blocked SHH signalling, but did not affect Notch signalling. ${ }^{94}$

\section{Hedgehog (SHH) pathway}

The SHH entity of $\mathrm{MB}$ accounts for approximately 30\% of all cases. It is driven by hedgehog ligands that undergo covalent modification by cholesterol ${ }^{97} 98$ and bind to the Patched (PTCH1) transmembrane receptor ${ }^{99}$ to maintain tumour growth and stemness. ${ }^{100-102}$ In a recent study by Bell et al, ${ }^{100}$ the authors used biomimetic high-density lipoprotein (HDL) nanoparticles to deplete cholesterol from hedgehog-driven $\mathrm{MB}$ and Ewing sarcoma cancer cells, via binding to the HDL receptor, scavenger receptor type $\mathrm{B}-1$, and thereby targeting the CSC populations in those tumours.

Among the other drivers of the $\mathrm{SHH}$ pathway is the protein patched homolog 1 (Ptch). ${ }^{103-105}$ A single tumour mouse model, namely the $\mathrm{Ptch}^{+/-}$model, has long been used to study the molecular and cellular mechanisms involved in $\mathrm{MB}$ formation, particularly $\mathrm{MB}^{\text {SHH }} \cdot{ }^{106} 107$ Chow et al ${ }^{103}$ provided evidence that although MBs that form in $\mathrm{Ptch}^{+/-} \mathrm{MB}$ mice are composed of three entities, all of them contain long-term, selfrenewing stem cell-like cells that are responsible for tumour initiation on serial in vivo transplantations. Other studies were also published confirming this. ${ }^{107} 108$ Notably, high expression levels of $\mathrm{PTCH} 2$ were observed in human MB tissues and correlated with a worse prognosis ${ }^{34}$; although PTCH2 is a tumour suppressor gene that inhibits $\mathrm{SHH}$ activity, ${ }^{109}$ its role in $\mathrm{MB}$ might not necessarily be related to $\mathrm{SHH}$ pathway inhibition but to GLI1 expression. ${ }^{34} 110$ This finding was further confirmed in a study by Po et al, ${ }^{105}$ where GLI1 and GLI2, the downstream effectors of SHH, were shown to bind to Nanogspecific cis-regulatory sequences in stem cells. In this regard, $\mathrm{SHH}$ signalling was linked to two distinct MB entities: wildtype TP53 (MB $\left.\mathrm{MB}^{\text {SHH-activated,TP53-wildtype }}\right)$ and TP53 loss ( $\mathrm{MB}^{\text {SHH- }}$ activated,TP53-mutant), a central event in promoting stemness, which contributes to Nanog upregulation in stem cells derived from both postnatal cerebellum and MB. ${ }^{105}$

\section{Notch pathway}

Like the SHH pathway, Notch signalling is required for controlling growth and proliferation of neural stem/progenitor cells as well as embryonal brain tumours, ${ }^{111}$ such as MB. ${ }^{20112-115}$ Fan $e t a l^{116}$ showed that MB stem-like cells exhibit higher levels of Notch signalling, which makes them more sensitive to this pathway inhibition. Indeed, Notch blockade with $\gamma$-secretase totally abolished CD133+ MB-CSCs, leading to loss of tumourforming capacity (due to depletion of stem-like cells). ${ }^{116}$ Another study by Pistollato et $a l^{117}$ revealed that hypoxic conditions promote Notch1 activation with its ligand Dll4 and lead to expansion of CD133+ and Nestin + MB precursors.

\section{PI3K pathway}

The phosphoinositide-3-kinase (PI3K)/AKT signalling pathway has been reported to play an important role in the renewal of embryonic stem cells. ${ }^{118} 119$ Recent studies also referred to the role of PI3K/AKT/mTOR pathway in growth and maintenance of CSCs in solid tumours, such as breast and prostate cancers. ${ }^{75} 120$ In MB, Frasson et $a l^{119}$ revealed that PI3K/AKT inhibition with LY294002 yielded increased cell death of CD133+ MB-CSCs and spared the more differentiated cells via activation of the mitochondrial apoptotic cascade. In another study by Hambardzumyan et al, ${ }^{121} 122$ the authors demonstrated that PI3K pathway plays a crucial role in regulating survival of nestin-expressing MB-CSCs residing in the PVN, and inhibition of AKT signalling sensitises PVN cells to radiation-induced apoptosis.

\section{MYC pathway}

MYC proteins have been associated with several cancers, including MB tumours ${ }^{31} 123$ that harbour MYC, MYCN and MYCL1 amplifications. ${ }^{118}$ In this regard, somatic mutations of TP53 had been mostly found in WNT-MB and SHH-MB and are associated with MYCN rather than MYC amplification. ${ }^{124}$

A study from the Chesler's group reported a genetically engineered mouse model of MYCN-driven MB (the GTML mouse model: Glt1-tTA (glutamate transporter 1-tetracycline transactivator), (TRE)-MYCN (tetracycline response element) and Luc (luciferase)), ${ }^{31}$ and later used this model to establish neurosphere lines. $^{32}$ Those spheres demonstrated robust proliferation and expressed neuronal markers such as Ngn1, Syp, Olig2 and Sox $9 .{ }^{125}$ Besides, when transplanted orthotopically into the brains of nude mice, the neurosphere lines were able to form massive tumours with morphology that mimicked human $M B$, including Homer Wright (neuroblastic) rosettes. ${ }^{32}$

Venkataraman et $a l^{126}$ conducted a study concluding that inhibition of a member of the bromodomain and extraterminal domain family, namely BRD4, effectively suppresses MYCdriven $\mathrm{MB}$ through attenuating cancer cells self-renewal, stem cell signalling and induction of senescence in vitro and in vivo. ${ }^{126}$

\section{Polycomb repressive complexes}

Polycomb repressive complexes 1 and 2 (PRC1 and PRC2) are evolutionarily conserved epigenetic regulators ${ }^{127}$ implicated in cancer. ${ }^{128}$ BMI1 (B cell-specific Moloney murine leukaemia virus integration site), the best studied PRC1 gene in oncology, ${ }^{129} 130$ is often overexpressed in cancer and has been implicated in maintaining tumour stemness by serving as a key CSC regulatory gene. $^{131} 132$ In MB, BMI1 is overexpressed across all subgroups, particularly $\mathrm{MB}^{\text {non-WNT/non-SHH, Group } 3.133134}$ A study by Wang et $a l^{134}$ revealed that SHH modulates BMI1 to maintain MB-CSCs. Another study by Bakhshinyan et al used a small-molecule inhibitor to target BMI1 in $\mathrm{MB}^{\text {non-WNT/non-SHH, Group3 }}$ cell lines, 
namely PTC-028, exemplifying significant reduction in stem cell properties in vitro and in vivo. BMI1 has also been shown to downregulate p53 in embryonal cancer precursor cells, such as neuroblastoma and $\mathrm{MB}$, and subsequently promote $\mathrm{MycN}$ oncoprotein overexpression in those cells. ${ }^{135}$ Manoranjan et $a l^{136}$ studied the stem cell data gathered from genomic platforms and demonstrated that FoxG1 interacts with Bmi1 in $\mathrm{MB}^{\text {non-WNT/ }}$ non-SHH, Group3 3 to mediate stem cell self-renewal and tumour initiation.

Another protein that represents the catalytically active component of the PRC2 is enhancer of zeste homologue 2 (EZH2). This protein causes chromatin compaction and contributes to several biological processes, including differentiation, maintaining cell identity and proliferation. ${ }^{137}$ It is shown to be highly expressed (more than twofold) in primary MB tissues and cell lines. ${ }^{138}$ Since it was proven that EZH2 maintains glioblastoma CSCs, ${ }^{139}$ Alimova et al evaluated the effects of knocking down EZH2 expression on MB-CSCs. Results showed that neurosphere formation was attenuated after EZH2 knockdown along with a significant decrease in Myc and Sox2 activities and G2 cell cycle arrest. ${ }^{138}$ The authors concluded that EZH2 might be a potential therapeutic target for $\mathrm{MB}$ and is important for $\mathrm{MB}$ cell growth and transformation of neural stem cells. ${ }^{138}$ In another study, an interaction between maternal embryonic leucine-zipper kinase and EZH2 was found in MB stem-like cells, representing an attractive therapeutic target and potential candidate for the diagnosis of $\mathrm{MB} .{ }^{140}$

\section{Other genetic aberrations}

Urokinase-type plasminogen activator receptor (uPAR) is a cell surface protein that drives directed extracellular proteolysis on the surface of invading cancer cells promoting invasion, migration and metastasis. ${ }^{141}$ It is overexpressed in the tumour-stromal invasive microenvironment in many human cancers, including $\mathrm{MB}{ }^{142}$ Asuthkar et $a l^{143}$ showed that IR induces the expression of uPAR and other CSC markers, such as MSI1 and CD44, and triggers WNT-7a- $\beta$-catenin signalling, which in turn promotes cancer stemness in MB. Overexpression of uPAR post-IR also negatively regulates Hand-1 activity, promoting angiogenesis via hypoxia-inducible factor- $1 \mathrm{a}$ upregulation. ${ }^{142}$ Henceforth, targeting uPAR in patients with MB undergoing IR might overcome potential therapy resistance and prevent IR-induced tumour angiogenesis. ${ }^{142} 143$

It is believed that in many tumours, drug resistance might be attributed to the efflux of chemotherapeutic drugs by key members of the ATP-binding cassette (ABC) transporter superfamily. ${ }^{144}$ Since a subpopulation of cells within tumours, namely CSCs, underlie tumour progression and relapse, those cells must express $\mathrm{ABC}$ transporters. ${ }^{145}$ Interestingly, in $\mathrm{MB}$, significant correlation was found between $\mathrm{ABCB} 1$ expression and high-risk tumours among patients with poorer overall survival. ${ }^{146}$

Polo-like kinase 1 (PLK1), a protein kinase that promotes mitosis via phosphorylating cyclin B1 and CDK1, ${ }^{147}$ is shown to be overexpressed in a wide variety of cancers, including MB. ${ }^{148}$ Inhibiting PLK1 by small-molecule inhibitor BI 2536 potently increased $\mathrm{MB}$ cellular apoptosis and sensitised cells to IR. It also reduced MB cell growth and CSC formation through decreasing the expression of SRY (sex determining region Y)-box 2 (SOX2). ${ }^{148}$

Lastly, accumulating evidence demonstrates a crucial role of microRNAs in regulating and maintaining CSCs within different tumours. In $\mathrm{MB}$, low expression of miR-466f-3p was found to sustain epithelial-to-mesenchymal transition in $\mathrm{MB}^{\text {SHH-activated }}$
CSCs via Vegfa-Nrp2 signalling pathway. ${ }^{149}$ Also, Kaid et al ${ }^{150}$ found that miR-367 enhances stemness features of MB cells, such as proliferation, 3D tumour spheroid cell invasion and the ability to generate CD133-expressing neurosphere-like structures. Other studied microRNAs included miR-135a, ${ }^{151}$ miR-142-3 p ${ }^{152}$ miR-218 $8^{153} 154$ and miR-34a. ${ }^{155}$

\section{CONCLUSIONS}

The key for effective eradication of $\mathrm{MB}$ tumours and overcoming aggravating therapy resistance is the isolation of the MB-CSCs and identification of their specific molecular signatures and genetic aberrations. This eventually will lead to the development of novel therapeutic interventions and combinations to target aggressive MB stem cell-specific dysregulations.

\section{Take home messages}

- Subpopulation of cells within the tumor, named cancer stem cells, are thought to be responsible for cancer recurrence in medulloblastoma.

- The key for effective eradication of medulloblastoma tumors and overcoming aggravating therapy resistance is isolation of cancer stem cells.

- Highly tumorigenic medulloblastoma cells display features imitating those of neural stem and progenitor cells, such as upregulation of CD133 and Nestin.

\section{Handling editor Dhirendra Govender}

Acknowledgements We would like to thank all members of the Arkadi M Rywlin MD Department of Pathology and Laboratory Medicine at Mount Sinai Medical Center for their help on this work.

Contributors HFB worked on the review conception and design. HFB screened titles for relevance, abstracted the data from eligible full-text articles, analysed and interpreted the data, and drafted the manuscript. RJP critically revised the manuscript. Both authors have read and approved the final draft.

Funding The authors have not declared a specific grant for this research from any funding agency in the public, commercial or not-for-profit sectors.

Competing interests None declared.

Patient consent for publication Not required.

Provenance and peer review Not commissioned; externally peer reviewed.

ORCID iD

Hisham F Bahmad http://orcid.org/0000-0003-3799-2595

\section{REFERENCES}

1 Martin AM, Raabe E, Eberhart C, et al. Management of pediatric and adult patients with medulloblastoma. Curr Treat Options Oncol 2014;15:581-94.

2 Crawford JR, MacDonald TJ, Packer RJ. Medulloblastoma in childhood: new biological advances. Lancet Neurol 2007;6:1073-85.

3 Rossi A, Caracciolo V, Russo G, et al. Medulloblastoma: from molecular pathology to therapy. Clin Cancer Res 2008;14:971-6.

4 Gilbertson RJ, Ellison DW. The origins of medulloblastoma subtypes. Annu Rev Pathol 2008:3:341-65.

5 Yokota N, Aruga J, Takai S, et al. Predominant expression of human Zic in cerebellar granule cell lineage and medulloblastoma. Cancer Res 1996;56:377-83.

6 Behesti H, Marino S. Cerebellar granule cells: insights into proliferation, differentiation, and role in medulloblastoma pathogenesis. Int J Biochem Cell Biol 2009;41:435-45.

7 Louis DN, Ohgaki H, Wiestler OD, et al. World Health organization classification of tumours of the central nervous system. 4th edn. Lyon: IARC Press, 2016.

8 Ostrom QT, Gittleman H, Truitt G, et al. CBTRUS statistical report: primary brain and other central nervous system tumors diagnosed in the United States in 2011-2015. Neuro Oncol 2018;20:iv1-86.

9 Dolecek T, Propp J, Stroup N, et al. CBTRUS (central brain tumor registry of the United States) statistical report: primary brain and central nervous system tumors diagnosed in the United States in 2005-2009. Neuro Oncol 2012;14:v1-49. 
10 Karajannis M, Allen JC, Newcomb EW. Treatment of pediatric brain tumors. J Cell Physiol 2008;217:584-9.

11 Packer RJ, Rood BR, MacDonald TJ. Medulloblastoma: present concepts of stratification into risk groups. Pediatr Neurosurg 2003;39:60-7.

12 Azzarelli R, Simons BD, Philpott A. The developmental origin of brain tumours: a cellular and molecular framework. Development 2018;145. doi:10.1242/dev.162693

13 Bahmad HF, Chamaa F, Assi S, et al. Cancer stem cells in neuroblastoma: expanding the therapeutic frontier. Front Mol Neurosci 2019;12.

14 Batlle E, Clevers H. Cancer stem cells revisited. Nat Med 2017;23:1124-34.

15 Moore MAS, Williams N, Metcalf $D$. In vitro colony formation by normal and leukemic human hematopoietic cells: characterization of the colony-forming cells 2. J Natl Cancer Inst 1973;50:603-23.

16 Singh SK, Clarke ID, Terasaki M, et al. Identification of a cancer stem cell in human brain tumors. Cancer Res 2003;63:5821-8.

17 Singh SK, Hawkins C, Clarke ID, et al. Identification of human brain tumour initiating cells. Nature 2004;432:396-401.

18 Calabrese $\mathrm{C}$, Poppleton $\mathrm{H}$, Kocak $\mathrm{M}$, et al. A perivascular niche for brain tumor stem cells. Cancer Cell 2007;11:69-82.

19 Fuchs E, Tumbar T, Guasch G. Socializing with the neighbors: stem cells and their niche. Cell 2004;116:769-78.

20 Fan X, Eberhart CG. Medulloblastoma stem cells. J Clin Oncol 2008;26:2821-7.

21 Ahmad Z, Jasnos L, Gil V, et al. Molecular and in vivo characterization of cancerpropagating cells derived from MYCN-dependent medulloblastoma. PLoS One 2015;10:e0119834.

22 Kaneko Y, Sakakibara S, Imai T, et al. Musashi1: an evolutionally conserved marker for CNS progenitor cells including neural stem cells. Dev Neurosci 2000;22:139-53.

23 Corno D, Pala M, Cominelli M, et al. Gene signatures associated with mouse postnatal hindbrain neural stem cells and medulloblastoma cancer stem cells identify novel molecular mediators and predict human medulloblastoma molecular classification. Cancer Discov 2012;2:554-68.

24 Louis DN, Ohgaki H, Wiestler OD, et al. The 2007 who classification of tumours of the central nervous system. Acta Neuropathol 2007:114:97-109.

25 Vriend J, Ghavami S, Marzban H. The role of the ubiquitin proteasome system in cerebellar development and medulloblastoma. Mol Brain 2015;8:64.

26 Gibson P, Tong Y, Robinson G, et al. Subtypes of medulloblastoma have distinct developmental origins. Nature 2010;468:1095-9.

27 Schüller U, Heine VM, Mao J, et al. Acquisition of granule neuron precursor identity is a critical determinant of progenitor cell competence to form Shh-induced medulloblastoma. Cancer Cell 2008;14:123-34.

28 Yang Z-J, Ellis T, Markant SL, et al. Medulloblastoma can be initiated by deletion of patched in lineage-restricted progenitors or stem cells. Cancer Cell 2008;14:135-45.

29 Pei Y, Moore CE, Wang J, et al. An animal model of Myc-driven medulloblastoma. Cancer Cell 2012;21:155-67.

30 Kawauchi D, Robinson G, Uziel T, et al. A mouse model of the most aggressive subgroup of human medulloblastoma. Cancer Cell 2012;21:168-80.

31 Swartling FJ, Grimmer MR, Hackett CS, et al. Pleiotropic role for MYCN in medulloblastoma. Genes Dev 2010;24:1059-72.

32 Swartling FJ, Savov V, Persson Al, et al. Distinct neural stem cell populations give rise to disparate brain tumors in response to N-myc. Cancer Cell 2012;21:601-13.

33 Varnum-Finney B, Xu L, Brashem-Stein C, et al. Pluripotent, cytokine-dependent, hematopoietic stem cells are immortalized by constitutive Notch1 signaling. Nat Med 2000:6:1278-81.

34 Cordeiro BM, Oliveira ID, Alves MTdeS, et al. SHH, WNT, and NOTCH pathways in medulloblastoma: when cancer stem cells maintain self-renewal and differentiation properties. Childs Nerv Syst 2014;30:1165-72.

35 Guessous F, Li Y, Abounader R. Signaling pathways in medulloblastoma. J Cell Physiol 2008:217:577-83.

36 Korshunov A, Savostikova M, Ozerov S. Immunohistochemical markers for prognosis of average-risk pediatric medulloblastomas. The effect of apoptotic index, TrkC, and c-myc expression. J Neurooncol 2002;58:271-9.

37 Aldosari N, Bigner SH, Burger PC, et al. Mycc and MYCN oncogene amplification in medulloblastoma. A fluorescence in situ hybridization study on paraffin sections from the children's Oncology Group. Arch Pathol Lab Med 2002;126:540-4.

38 Grotzer MA, Hogarty MD, Janss AJ, et al. Myc messenger RNA expression predicts survival outcome in childhood primitive neuroectodermal tumor/medulloblastoma. Clin Cancer Res 2001;7:2425-33.

39 Min HS, Lee YJ, Park K, et al. Medulloblastoma: histopathologic and molecular markers of anaplasia and biologic behavior. Acta Neuropathol 2006;112:13-20.

40 Ray A, Ho M, Ma J, et al. A clinicobiological model predicting survival in medulloblastoma. Clin Cancer Res 2004;10:7613-20.

41 Haberler C, Slavc I, Czech T, et al. Histopathological prognostic factors in medulloblastoma: high expression of survivin is related to unfavourable outcome. Eur J Cancer 2006;42:2996-3003.

42 Huang G-H, Xu Q-F, Cui Y-H, et al. Medulloblastoma stem cells: promising targets in medulloblastoma therapy. Cancer Sci 2016;107:583-9.

43 Huang $X$, Ketova T, Lltingtung $Y$, et al. Isolation, enrichment, and maintenance of medulloblastoma stem cells. JoVE 2010
44 Zanini C, Ercole E, Mandili G, et al. Medullospheres from DAOY, UW228 and ONS76 cells: increased stem cell population and proteomic modifications. PLoS One 2013:8:e63748

45 Srivastava VK, Nalbantoglu J. Flow cytometric characterization of the DAOY medulloblastoma cell line for the cancer stem-like phenotype. Cytometry Part $A$ 2008:73A:940-8.

46 Srivastava VK, Nalbantoglu J. The cellular and developmental biology of medulloblastoma: current perspectives on experimental therapeutics. Cancer Biol Ther 2010;9:843-52.

47 Sümer-Turanlıgil NC, Cetin Emel Öykü, Uyanıkgil Y. A contemporary review of molecular candidates for the development and treatment of childhood medulloblastoma. Childs Nerv Syst 2013;29:381-8.

48 Chopin V, Lagadec C, Toillon R-A, et al. Neurotrophin signaling in cancer stem cells. Cell Mol Life Sci 2016;73:1859-70.

49 Lowry NA, Temple S. Identifying the perpetrator in medulloblastoma: Dorian gray versus Benjamin button. Cancer Cell 2009;15:83-5.

50 Read T-A, Fogarty MP, Markant SL, et al. Identification of CD15 as a marker for Tumor-Propagating cells in a mouse model of medulloblastoma. Cancer Cell 2009:15:135-47.

51 Ward RJ, Lee L, Graham K, et al. Multipotent CD15+ cancer stem cells in patched-1deficient mouse medulloblastoma. Cancer Res 2009;69:4682-90.

52 Zhu G, Rankin SL, Larson JD, et al. Pten signaling in the postnatal perivascular progenitor niche drives medulloblastoma formation. Cancer Res 2017;77:123-33.

53 Elbadawy M, Usui T, Yamawaki H, et al. Emerging roles of c-myc in cancer stem cell-related signaling and resistance to cancer chemotherapy: a potential therapeutic target against colorectal cancer. Int J Mo/ Sci 2019;20:2340.

54 Zhang H-L, Wang P, M-Z L, et al. C-Myc maintains the self-renewal and chemoresistance properties of colon cancer stem cells. Oncol Lett 2019:17:4487-93.

55 Yang A, Qin S, Schulte BA, et al. Myc inhibition depletes cancer stem-like cells in triple-negative breast cancer. Cancer Res 2017;77:6641-50.

56 Wang $X$, Sun Y, Wong J, et al. Ppary maintains ErbB2-positive breast cancer stem cells. Oncogene 2013;32:5512-21.

57 Pandit H, Li Y, Li X, et al. Enrichment of cancer stem cells via $\beta$-catenin contributing to the tumorigenesis of hepatocellular carcinoma. BMC Cancer 2018; 18:783-83.

58 Valkenburg KC, Graveel CR, Zylstra-Diegel CR, et al. Wnt/3-catenin Signaling in Normal and Cancer Stem Cells. Cancers 2011:3:2050-79.

59 Yamamoto M, Suzuki S, Togashi K, et al. AS602801, an anticancer stem cell candidate drug, reduces survivin expression and sensitizes A2780 ovarian cance stem cells to carboplatin and paclitaxel. Anticancer Res 2018;38:6699-706.

60 Ejarque M, Ceperuelo-Mallafré V, Serena C, et al. Survivin, a key player in cancer progression, increases in obesity and protects adipose tissue stem cells from apoptosis. Cell Death Dis 2017:8:e2802.

61 Chen X, Guan H, Liu X-D, et al. P53 positively regulates the expression of cancer stem cell marker CD133 in HCT116 colon cancer cells. Oncol Lett 2018;16:431-8.

62 Flores DG, Ledur PF, Abujamra AL, et al. Cancer stem cells and the biology of brain tumors. Curr Stem Cell Res Ther 2009;4:306-13.

63 Raso A, Mascelli S, Biassoni R, et al. High levels of PROM1 (CD133) transcript are a potential predictor of poor prognosis in medulloblastoma. Neuro Oncol 2011;13:500-8

64 Rodini CO, Suzuki DE, Nakahata AM, et al. Aberrant signaling pathways in medulloblastomas: a stem cell connection. Arq Neuropsiquiatr 2010;68:947-52.

65 Kumar V, Kumar V, McGuire T, et al. Challenges and recent advances in medulloblastoma therapy. Trends Pharmacol Sci 2017;38:1061-84.

66 Manoranjan B, Garg N, Bakhshinyan D, et al. The role of stem cells in pediatric central nervous system malignancies. Adv Exp Med Biol 2015;853:49-68.

67 Manoranjan B, Venugopal C, McFarlane N, et al. Medulloblastoma stem cells: where development and cancer cross pathways. Pediatr Res 2012;71:516-22.

68 Manoranjan B, Venugopal C, McFarlane N, et al. Medulloblastoma stem cells: modeling tumor heterogeneity. Cancer Lett 2013;338:23-31.

69 Glumac PM, LeBeau AM. The role of CD133 in cancer: a Concise review. Clin Trans/ Med 2018;7:18

70 Bisson I, Prowse DM. Wnt signaling regulates self-renewal and differentiation of prostate cancer cells with stem cell characteristics. Cell Res 2009;19:683-97.

71 Mak AB, Nixon AML, Kittanakom S, et al. Regulation of CD133 by HDAC6 promotes $\beta$-catenin signaling to suppress cancer cell differentiation. Cell Rep 2012:2:951-63.

72 Zhukova N, Ramaswamy V, Remke M, et al. Wnt activation by lithium abrogates TP53 mutation associated radiation resistance in medulloblastoma. Acta Neuropathologica Communications 2014;2.

73 Bassani B, Bartolini D, Pagani A, et al. Fenretinide (4-HPR) targets caspase-9, ERK $1 / 2$ and the Wnt3a/ $\beta$-Catenin pathway in medulloblastoma cells and medulloblastoma cell spheroids. PLoS One 2016;11:e0154111.

74 Wei Y, Jiang Y, Zou F, et al. Activation of PI3K/Akt pathway by CD133-p85 interaction promotes tumorigenic capacity of glioma stem cells. Proc Natl Acad Sci U S A 2013:110:6829-34.

75 Dubrovska A, Kim S, Salamone RJ, et al. The role of PTEN/Akt/PI3K signaling in the maintenance and viability of prostate cancer stem-like cell populations. Proc Natl Acad Sci U S A 2009;106:268-73. 
76 de la Rosa J, Sáenz Antoñanzas A, Shahi MH, et al. Laminin-Adherent versus suspension-non-adherent cell culture conditions for the isolation of cancer stem cells in the DAOY medulloblastoma cell line. Tumor Biology 2016;37:12359-70.

77 Blazek ER, Foutch JL, Maki G. Daoy medulloblastoma cells that express CD133 are radioresistant relative to CD133- cells, and the CD133+ sector is enlarged by hypoxia. Int J Radiat Oncol Biol Phys 2007;67:1-5.

78 Dean M, Fojo T, Bates S. Tumour stem cells and drug resistance. Nat Rev Cancer 2005:5:275-84.

79 Annabi B, Doumit J, Plouffe K, et al. Members of the low-density lipoprotein receptor-related proteins provide a differential molecular signature between parental and CD133(+) DAOY medulloblastoma cells. Mol Carcinog 2010;218:n/a-7.

80 Annabi B, Rojas-Sutterlin S, Laflamme C, et al. Tumor environment dictates medulloblastoma cancer stem cell expression and invasive phenotype. Molecular Cancer Research 2008;6:907-16.

81 Greenhough A, Smartt HJM, Moore AE, et al. The COX-2/PGE2 pathway: key roles in the hallmarks of cancer and adaptation to the tumour microenvironment. Carcinogenesis 2009:30:377-86.

82 Dannenberg AJ, Altorki NK, Boyle JO, et al. Cyclo-Oxygenase 2: a pharmacological target for the prevention of cancer. Lancet Oncol 2001:2:544-51.

83 Baryawno N, Sveinbjörnsson B, Eksborg S, et al. Tumor-growth-promoting cyclooxygenase-2 prostaglandin E2 pathway provides medulloblastoma therapeutic targets. Neuro Oncol 2008;10:661-74.

84 Masferrer JL, Leahy KM, Koki AT, et al. Antiangiogenic and antitumor activities of cyclooxygenase-2 inhibitors. Cancer Res 2000;60:1306-11.

85 Chen K-H, Hsu C-C, Song W-S, et al. Celecoxib enhances radiosensitivity in medulloblastoma-derived CD133-positive cells. Child's Nervous System 2010;26:1605-12.

86 Yang M-Y, Lee H-T, Chen C-M, et al. Celecoxib suppresses the phosphorylation of STAT3 protein and can enhance the radiosensitivity of medulloblastoma-derived cancer stem-like cells. Int J Mol Sci 2014;15:11013-29.

$87 \mathrm{KH} \mathrm{L}$, Chen YW, Tsai PH, et al. Evaluation of radiotherapy effect in resveratrol-treated medulloblastoma cancer stem-like cells child's nervous system. Child s Nervous System 2009;25:543-50.

88 Chen S-M, Li Y-Y, Tu C-H, et al. Blockade of inhibitors of apoptosis proteins in combination with conventional chemotherapy leads to synergistic antitumor activity in medulloblastoma and cancer stem-like cells. PLoS One 2016;11:e0161299.

89 Chang C-J, Chiang C-H, Song W-S, et al. Inhibition of phosphorylated STAT3 by cucurbitacin I enhances chemoradiosensitivity in medulloblastoma-derived cancer stem cells. Child's Nervous System 2012;28:363-73.

90 Garg N, Bakhshinyan D, Venugopal C, et al. Cd133+ brain tumor-initiating cells are dependent on STAT3 signaling to drive medulloblastoma recurrence. Oncogene 2017;36:606-17

91 Ray S, Coulter DW, Gray SD, et al. Suppression of STAT3 NH -terminal domain chemosensitizes medulloblastoma cells by activation of protein inhibitor of activated STAT3 via de-repression by microRNA-21. Mol Carcinog 2018;57:536-48.

92 Dietl S, Schwinn S, Dietl S, et al. MB3W1 is an orthotopic xenograft model for anaplastic medulloblastoma displaying cancer stem cell- and group 3-properties. BMC Cancer 2016;16:115.

93 Friedman GK, Moore BP, Nan L, et al. Pediatric medulloblastoma xenografts including molecular subgroup 3 and CD133+ and CD15+ cells are sensitive to killing by oncolytic herpes simplex viruses. Neuro Oncol 2016;18:227-35.

94 Lim KJ, Bisht S, Bar EE, et al. A polymeric nanoparticle formulation of curcumin inhibits growth, clonogenicity and stem-like fraction in malignant brain tumors. Cancer Biol Ther 2011;11:464-73.

95 Hatcher $\mathrm{H}$, Planalp R, Cho J, et al. Curcumin: from ancient medicine to current clinical trials. Cell Mol Life Sci 2008;65:1631-52.

96 Maheshwari RK, Singh AK, Gaddipati J, et al. Multiple biological activities of curcumin: a short review. Life Sci 2006;78:2081-7.

97 Xiao X, Tang J-J, Peng C, et al. Cholesterol modification of smoothened is required for hedgehog signaling. Mol Cell 2017;66:154-62.

98 Hentschel A, Zahedi RP, Ahrends R. Protein lipid modifications--More than just a greasy ballast. Proteomics 2016;16:759-82.

99 Wu F, Zhang Y, Sun B, et al. Hedgehog signaling: from basic biology to cancer therapy. Cell Chemical Biology 2017;24:252-80.

100 Bell JB, Rink JS, Eckerdt F, et al. Hdl nanoparticles targeting sonic hedgehog subtype medulloblastoma. Sci Rep 2018:8:1211.

101 Enguita-Germán M, Schiapparelli P, Rey JA, et al. Cd133+ cells from medulloblastoma and PNET cell lines are more resistant to cyclopamine inhibition of the sonic hedgehog signaling pathway than CD133-cells. Tumour Biol 2010:31:381-90.

102 Ronci M, Catanzaro G, Pieroni L, et al. Proteomic analysis of human sonic hedgehog (Shh) medulloblastoma stem-like cells. Mol Biosyst 2015;11:1603-11.

103 Chow K-H, Shin D-M, Jenkins MH, et al. Epigenetic states of cells of origin and tumor evolution drive tumor-initiating cell phenotype and tumor heterogeneity. Cancer Res 2014:74:4864-74.

104 Po A, Abballe L, Sabato C, et al. Sonic hedgehog medulloblastoma cancer stem cells Mirnome and transcriptome highlight novel functional networks. Int J Mo/ Sci 2018;19:2326
105 Po A, Ferretti E, Miele E, et al. Hedgehog controls neural stem cells through p53independent regulation of Nanog. Embo J 2010;29:2646-58.

106 Corcoran RB, Scott MP. A mouse model for medulloblastoma and basal cell nevus syndrome. J Neurooncol 2001:53:307-18.

107 Tanori M, Pannicelli A, Pasquali E, et al. Cancer risk from low dose radiation in Ptch1/ mice with inactive DNA repair systems: therapeutic implications for medulloblastoma. DNA Repair 2019;74:70-9.

108 Tanno B, Leonardi S, Babini G, et al. Nanog-driven cell-reprogramming and selfrenewal maintenance in PTCH1 +/- granule cell precursors after radiation injury. SCi Rep 2017:7:14238.

109 Rahnama F, Toftgård R, Zaphiropoulos PG. Distinct roles of PTCH2 splice variants in hedgehog signalling. Biochem J 2004;378:325-34.

110 Miele E, Po A, Begalli F, et al. $\beta$-arrestin1-mediated acetylation of Gli1 regulates Hedgehog/Gli signaling and modulates self-renewal of SHH medulloblastoma cancer stem cells. BMC Cancer 2017:17:488.

111 Pierfelice TJ, Schreck KC, Eberhart CG, et al. Notch, neural stem cells, and brain tumors. Cold Spring Harb Symp Quant Biol 2008;73:367-75.

112 Raffel C, Jenkins RB, Frederick L, et al. Sporadic medulloblastomas contain PTCH mutations. Cancer Res 1997:57:842-5.

113 Reifenberger J, Wolter M, Weber RG, et al. Missense mutations in SMOH in sporadic basal cell carcinomas of the skin and primitive neuroectodermal tumors of the central nervous system. Cancer Res 1998;58:1798-803.

114 Eberhart CG, Tihan T, Burger PC. Nuclear localization and mutation of $\beta$-catenin in medulloblastomas. J Neuropathol Exp Neurol 2000:59:333-7.

115 Wang $Y$, Wang $Y$, Chen $\mathrm{H}$, et al. Endothelial cells promote formation of medulloblastoma stem-like cells via Notch pathway activation. J Mol Neurosci 2017;63:152-8

116 Fan X, Matsui W, Khaki L, et al. Notch pathway inhibition depletes stemlike cells and blocks engraftment in embryonal brain tumors. Cancer Res 2006;66:7445-52.

117 Pistollato F, Rampazzo E, Persano L, et al. Interaction of hypoxia-inducible factor-1 $\alpha$ and Notch signaling regulates medulloblastoma precursor proliferation and fate Stem Cells 2010:28:1918-29.

118 Northcott PA, Shih DJH, Peacock J, et al. Subgroup-Specific structural variation across 1,000 medulloblastoma genomes. Nature 2012:488:49-56.

119 Frasson C, Rampazzo E, Accordi B, et al. Inhibition of PI3K signalling selectively affects medulloblastoma cancer stem cells. Biomed Res Int 2015:2015:1-11.

120 Zhou J, Wulfkuhle J, Zhang H, et al. Activation of the PTEN/mTOR/STAT3 pathway in breast cancer stem-like cells is required for viability and maintenance. Proc Natl Acad Sci U S A 2007;104:16158-63.

121 Hambardzumyan D, Becher OJ, Rosenblum MK, et al. Pi3K pathway regulates survival of cancer stem cells residing in the perivascular niche following radiation in medulloblastoma in vivo. Genes Dev 2008;22:436-48.

122 Hambardzumyan D, Becher OJ, Holland EC. Cancer stem cells and survival pathways. Cell Cycle 2008;7:1371-8.

123 Roussel MF, Robinson GW. Role of MYC in medulloblastoma. Cold Spring Harb Perspect Med 2013;3:a014308.

124 Pfaff $\mathrm{E}$, Remke $\mathrm{M}$, Sturm $\mathrm{D}$, et al. Tp53 mutation is frequently associated with CTNNB1 mutation or MYCN amplification and is compatible with long-term survival in medulloblastoma. J Clin Oncol 2010:28:5188-96.

125 Becher OJ, Holland EC. Sox2, a marker for stem-like tumor cells in skin squamous cell carcinoma and hedgehog subgroup medulloblastoma. Embo J 2014;33:1984-6.

126 Venkataraman S, Alimova I, Balakrishnan I, et al. Inhibition of BRD4 attenuates tumor cell self-renewal and suppresses stem cell signaling in Myc driven medulloblastoma. Oncotarget 2014:5:2355-71.

127 Schuettengruber B, Bourbon H-M, Di Croce L, et al. Genome regulation by polycomb and trithorax: 70 years and counting. Cell 2017:171:34-57.

128 Chan HL, Beckedorff F, Zhang Y, et al. Polycomb complexes associate with enhancers and promote oncogenic transcriptional programs in cancer through multiple mechanisms. Nat Commun 2018;9:3377.

129 Chowdhury M, Mihara K, Yasunaga S, et al. Expression of polycomb-group (PcG) protein Bmi-1 predicts prognosis in patients with acute myeloid leukemia. Leukemia 2007:21:1116-22.

130 Nacerddine K, Beaudry J-B, Ginjala V, et al. Akt-Mediated phosphorylation of BMI1 modulates its oncogenic potential, E3 ligase activity, and DNA damage repair activity in mouse prostate cancer. J Clin Invest 2012:122:1920-32.

131 Sauvageau M, Sauvageau G. Polycomb group proteins: multi-faceted regulators of somatic stem cells and cancer. Cell Stem Cell 2010;7:299-313.

132 Sparmann A, van Lohuizen M. Polycomb silencers control cell fate, development and cancer. Nat Rev Cancer 2006:6:846-56.

133 Leung $C$, Lingbeek M, Shakhova 0 , et al. Bmi1 is essential for cerebellar development and is overexpressed in human medulloblastomas. Nature 2004:428:337-41.

134 Wang X, Venugopal C, Manoranjan B, et al. Sonic hedgehog regulates Bmi1 in human medulloblastoma brain tumor-initiating cells. Oncogene 2012;31:187-99.

135 Calao M, Sekyere EO, Cui HJ, et al. Direct effects of BMI1 on p53 protein stability inactivates oncoprotein stress responses in embryonal cancer precursor cells at tumor initiation. Oncogene 2013;32:3616-26. 
136 Manoranjan B, Wang X, Hallett RM, et al. Foxg1 interacts with BMI1 to regulate self-renewal and tumorigenicity of medulloblastoma stem cells. Stem Cells 2013;31:1266-77.

137 Margueron R, Reinberg D. The polycomb complex PRC2 and its mark in life. Nature 2011;469:343-9.

138 Alimova I, Venkataraman S, Harris P, et al. Targeting the enhancer of zeste homologue 2 in medulloblastoma. Int J Cancer 2012;131:1800-9.

139 Suva M-L, Riggi N, Janiszewska M, et al. Ezh2 is essential for glioblastoma cancer stem cell maintenance. Cancer Res 2009;69:9211-8.

140 Liu H, Sun Q, Sun Y, et al. Melk and EZH2 cooperate to regulate medulloblastoma cancer stem-like cell proliferation and differentiation. Molecular Cancer Research 2017;15:1275-86.

141 Waltz DA, Natkin LR, Fujita RM, et al. Plasmin and plasminogen activator inhibitor type 1 promote cellular motility by regulating the interaction between the urokinase receptor and vitronectin. J Clin Invest 1997;100:58-67.

142 Asuthkar S, Gogineni VR, Rao JS, et al. Nuclear translocation of Hand-1 acts as a molecular switch to regulate vascular radiosensitivity in medulloblastoma tumors: the protein UPAR is a cytoplasmic sequestration factor for Hand-1. Mol Cancer Ther 2014;13:1309-22.

143 Asuthkar S, Gondi CS, Nalla AK, et al. Urokinase-type plasminogen activator receptor (UPAR)-mediated regulation of WNT/ $\beta$-catenin signaling is enhanced in irradiated medulloblastoma cells. J Bio/ Chem 2012;287:20576-89.

144 Szakács G, Paterson JK, Ludwig JA, et al. Targeting multidrug resistance in cancer. Nat Rev Drug Discov 2006;5:219-34.

145 Coyle B, Kessler M, Sabnis DH, et al. Abcb1 in children's brain tumours. Biochem Soc Trans 2015;43:1018-22.
146 Othman RT, Kimishi I, Bradshaw TD, et al. Overcoming multiple drug resistance mechanisms in medulloblastoma. Acta Neuropathol Commun 2014;2.

147 Strebhardt K. Multifaceted polo-like kinases: drug targets and antitargets for cancer therapy. Nat Rev Drug Discov 2010;9:643-60.

148 Harris PS, Venkataraman S, Alimova I, et al. Polo-Like kinase 1 (Plk1) inhibition suppresses cell growth and enhances radiation sensitivity in medulloblastoma cells. BMC Cancer 2012;12:80.

149 Besharat ZM, Sabato C, Po A, et al. Low expression of miR-466f-3p sustains epithelial to mesenchymal transition in sonic hedgehog medulloblastoma stem cells through Vegfa-Nrp2 signaling pathway. Front Pharmacol 2018;9:1281-81.

150 Kaid C, Silva PBG, Cortez BA, et al. miR-367 promotes proliferation and stem-like traits in medulloblastoma cells. Cancer Sci 2015;106:1188-95.

151 Hemmesi K, Squadrito ML, Mestdagh P, et al. miR-135a Inhibits Cancer Stem CellDriven Medulloblastoma Development by Directly Repressing Arhgef6 Expression. Stem Cells 2015;33:1377-89.

152 Lee $Y$-Y, Yang Y-P, Huang M-C, et al. MicroRNA142-3p promotes tumor-initiating and radioresistant properties in malignant pediatric brain tumors. Cell Transplant 2014;23:669-90.

153 Venkataraman S, Birks DK, Balakrishnan I, et al. Microrna 218 acts as a tumor suppressor by targeting multiple cancer phenotype-associated genes in medulloblastoma. J Biol Chem 2013;288:1918-28.

154 Venkataraman S, Alimova I, Fan R, et al. Microrna 128a increases intracellular ROS level by targeting Bmi-1 and inhibits medulloblastoma cancer cell growth by promoting senescence. PLoS One 2010;5:e10748.

155 de Antonellis P, Medaglia C, Cusanelli E, et al. Mir-34A targeting of Notch ligand delta-like 1 impairs CD15+/CD133+ tumor-propagating cells and supports neural differentiation in medulloblastoma. PLoS One 2011;6:e24584. 